\title{
Systematic review and meta-analysis of cancer studies evaluating diagnostic test accuracy and prognostic values: approaches to improve clinical interpretation of results
}

This article was published in the following Dove Press journal:

Cancer Management and Research

\author{
Rama Jayaraj' \\ Chellan Kumarasamy² \\ 'College of Health and Human \\ Sciences, Charles Darwin University, \\ Ellengowan Drive, Darwin, Northern \\ Territory, Australia; ${ }^{2}$ The University \\ of Adelaide, North Terrace Campus, \\ Adelaide, South Australia, Australia
}

Correspondence: Rama Jayaraj College of Health and Human Sciences, Charles Darwin University, Ellengowan Drive, Darwin, NT 0909, Australia Email Rama.Jayaraj@cde.edu.au

\section{Dear editor}

The article, "Diagnostic and prognostic value of microRNAs in cholangiocarcinoma: a systematic review and meta-analysis", published by Sun et al in the Cancer Management and Research journal, has caught our attention. ${ }^{1}$ There are only few studies available on the subject of prognostic and diagnostic markers in cholangiocarcinoma, when compared with the literature available on other forms of cancer. For this reason, we believe that Sun et al's study can be a valid reference point for future studies in this field. However, we have a few valid suggestions and approaches on regarding the article, which may help improve its quality, as well as its capability to inform future research.

Analysis of heterogeneity between diagnostic test accuracy studies: the study by Sun et $\mathrm{al}^{1}$ has used the Chi-squared statistics to test against the null hypothesis and the I-squared statistics to study heterogeneity, but both these statistical values do not consider the threshold effect. It might be beneficial to also include the Tau-squared statistics as a part of the statistical analysis performed in this study. Tau-squared statistics is the estimated variation between the effects for test accuracy observed in different studies. ${ }^{2}$ Its inclusion in Sun et al's study will provide a more comprehensive statistical analysis.

Ubiquitous expression of miR-21 in all cancers: furthermore, the study concludes that miR-21 is a potential diagnostic and prognostic marker for cholangiocarcinoma. The issue lies in the fact that miR-21 has been found to be ubiquitously expressed in nearly all forms of cancer, with most studies concluding that miR-21 has great potential as a diagnostic marker and its expression is significantly correlated with patient survival. This ubiquitous expression of miR-21 significantly reduces the clinical utility of miR-21 as a diagnostic or prognostic marker as its expression is not specific to cholangiocarcinoma alone. As an example, we can consider Jinling et al's study where miR-21 expression was found to be capable of predicting poor prognosis in breast cancer patients, which contradicts with Sun et al's study where miR-21 is suggested a marker to uniquely identify cholangiocarcinoma cases. ${ }^{3}$ This is a line of discussion that must be elaborated on and included in the study by the authors, both to validate the study's results and to serve as a reference point for future research.

We believe that this is a valuable study that would better serve the scientific community if these issues were addressed and would also help maintain a high standard for similar future studies. 


\section{Acknowledgment}

This research received no specific grant from any funding agency in public, commercial, or not-for-profit sectors.

\section{Author contributions}

$\mathrm{RJ}$ conceived this study and provided supervision and mentorship to CK. RJ led the development of the study protocol and design, wrote the first draft of the protocol, coordinated and integrated comments from co-author CK, edited successive drafts of the manuscript, and gave input to the final draft of the protocol. All authors contributed toward data analysis, drafting and critically revising the paper and agree to be accountable for all aspects of the work.

\section{Disclosure}

The authors report no conflicts of interest in this communication.

\section{References}

1. Sun C, Zhu J, Wu B, et al. Diagnostic and prognostic value of microRNAs in cholangiocarcinoma: a systematic review and meta-analysis. Cancer Manag Res. 2018;10:2125-2139.

2. Kim KW, Lee J, Choi SH, Huh J, Park SH. Systematic review and metaanalysis of studies evaluating diagnostic test accuracy: a practical review for clinical researchers-part I. general guidance and tips. Korean J Radiol. 2015;16(6):1175-1187.

3. Jinling W, Sijing S, Jie Z, Guinian W. Prognostic value of circulating microRNA-21 for breast cancer: a systematic review and meta-analysis. Artif Cells Nanomed Biotechnol. 2017;45(6):1216-1221.

Dove Medical Press encourages responsible, free and frank academic debate. The content of the Cancer Management and Research 'letters to the editor' section does not necessarily represent the views of Dove Medical Press, its officers, agents, employees, related entities or the Cancer Management and Research editors. While all reasonable steps have been taken to confirm the content of each letter, Dove Medical Press accepts no liability in respect of the content of any letter, nor is it responsible for the content and accuracy of any letter to the editor.

\section{Publish your work in this journal}

Cancer Management and Research is an international, peer-reviewed open access journal focusing on cancer research and the optimal use of preventative and integrated treatment interventions to achieve improved outcomes, enhanced survival and quality of life for the cancer patient. The manuscript management system is completely online and includes a very quick and fair peer-review system, which is all easy to use. Visit
$\mathrm{http}: / / \mathrm{www}$.dovepress.com/testimonials.php to read real quotes from published authors. 